\title{
MUNdO DA VIDA E DIREITO: UMA ABORDAGEM A PARTIR DE HABERMAS
}

\author{
[LIFEWORLD AND LAW: AN APPROACH FROM HABERMAS]
}

\author{
Keberson Bresolin* \\ Maicon da Silva** \\ Universidade Federal de Pelotas, Brasil
}

\begin{abstract}
Resumo: O presente artigo visa tomar esclarecimento sobre o conceito de mundo da vida (Lebenswelt) e a sua relação com o direito. Ele foi estruturado da seguinte forma: primeiramente passaremos por algumas ponderações sobre a gênese do mundo da vida. $\mathrm{Na}$ sequência abordaremos a concepção de mundo da vida de Habermas. Neste sentido, estaremos aptos para verticalizar o entendimento sobre os três mundos formais da Teoria da Ação Comunicativa de Habermas. E com isto, iremos tramitar entre os componentes das estruturas do mundo da vida, bem como, a racionalização dela. Finalmente, abordaremos a colonização do mundo da vida e o papel do direito na integração social.
\end{abstract}

Palavras-chave: Jürgen Habermas; mundo da vida; teoria do agir comunicativo; integração social
ABstract: This paper aims to clarify Habermas' concept of the life world and its relationship with law. It was structured in the following way: first we will go through some considerations about the genesis of the life world. In the sequence, we will approach Habermas' worldview of life. In this sense, we will be able to verticalize the understanding of the three formal worlds of Habermas' Theory of Communicative Action. And with this, we will proceed between the components of the structures of the life world, as well as, its rationalization. Finally, we will address the colonization of the life world and the role of law in social integration.

KEYwORDS: Habermas; life world; law; social integration; system

\section{CONSIDERAÇÕES INICIAIS}

A filosofia tardia de Husserl tinha como objetivo levantar alguns problemas da vida social com uma teoria capaz de dar soluções para ele. Diferentemente de sua intenção propositiva para uma leitura do social, as teorias cientificistas de sua época apresentavam-se como conhecimento predominante.

Interessantemente, então, o filósofo que apresenta a estrutura de seu pensamento voltada à consciência, e que interpreta o mundo apenas como constituídos de fenômenos de objetos que se apresentam na consciência, quase, paradoxalmente, volta o olhar para a história e o social. A teoria científica tão abundante na resolução de problemas que outrora foram insolúveis, se apresentou no século XIX com um aspecto salvificador para

* Professor do Programa de Pós-Graduação em Filosofia da Universidade Federal de Pelotas. Email: keberson.bresolin@gmail.com. ** Licenciando em Filosofia na Universidade Federal de Pelotas e bolsista de Iniciação Científica FAPERGS (2019) e CNPq (2019-2020). Pesquisador, participante, apresentador e interlocutor do Grupo Filosofia Politica e do Direito coordenado pelo Prof. Dr. Keberson Bresolin, de onde este artigo surgiu. E-mail: maicondasilva@gmail.com 
humanidade. A ciência realmente proporcionou soluções e avanços imensuráveis como os da astronomia, da física e da medicina. Em contrapartida, o desenvolvimento aliado à ideia de progresso e desenvolvimento nem sempre resultou em uma sociedade integrada.

Husserl, que esteve está envolto em uma crise política com a ascensão do

156 nazismo ao poder. Momento político e histórico vivido por ele e que comprovam que os efeitos do desenvolvimento técnico e científico agravaram a catástrofe da segunda guerra mundial. Isso nos coloca a questão de que a ciência não anda de mãos dadas com o estudo da vida em sociedade, ou seja, o estudo da sociedade requer outra fonte teorética.

O presente estudo será construído de modo a pontuar os principais movimentos da teoria da comunicação de Habermas, sempre com olhar voltado para o mundo da vida e a integração social.

\section{O MUNDO DA VIDA: APPROACH 1}

A ideia de mundo da vida (Lebenswelt) nasce, poderíamos afirmar, com a fenomenologia do Husserl. Apesar da aparente divergência entre fenomenologia e sociologia, Husserl sustenta em suas últimas obras um estudo intrigante sobre a vida social. Como mencionado, a teoria científica não pareceu ser capaz de enfrentar e solucionar todos os problemas do social. O mundo subjetivo e intersubjetivo apresenta um grande dinamismo o qual é possível perceber, sobretudo, na pluralidade dos Estados democráticos contemporâneos.

A abordagem de Husserl segue em um retorno aos meios sociais mais primitivos para pensar a ideia de mundo da vida. Husserl retorna a modos de vida da Grécia antiga para a investigação da vida de uma "nova" humanidade surgida na Grécia e, por conseguinte, o começo daquilo que viria ser as ciências que conhecemos hoje (Cf. HUSSERL, 2012. p. 99.). Não obstante, antes dos gregos antigos estávamos em relações puramente humanas e desengatadas da ciência universal (filosofia) e das ciências em geral que, por seu turno, surgiram a partir daí. Nesta esteira de pensamento, Husserl apresenta o conceito de mundo da vida:

Este é naturalmente pré-dado a todos nós, como pessoas o horizonte da nossa cohumanidade, ou seja, em cada conexão real com o outro, pré-dado como "o" mundo, o universal-comum. Ele é [...] o solo permanente de validade, uma fonte constantemente pronta de obviedades a que recorremos sem mais, como homens práticos ou como cientistas. (HUSSERL, 2012. p. 99).

Podemos inferir, a partir do excerto, uma diferenciação entre o que é estudo da sociedade e o que é ciência, ou seja, a valorização do "pré" ao invés de sua neutralidade e eliminação na eminencia da construção de um sujeito desenraizado. Ainda, notamos a preocupação de Husserl em formular uma filosofia de análise social, a qual, por sua vez, encontra-se na história e na linguagem. Em outras palavras, o mundo da vida para Husserl é a vida em uma sociedade na qual o engate e estabilidade social se dá por meio história e linguagem. Elementos necessários para a fuga de um solipsismo na epistemologia fenomenológica que ele não se afastará.

A valorização da história e da linguagem e um possível abandono de um sujeito solipsista e meta-histórico é questionado justamente em razão da aparente 
incompatibilidade entre a fenomenologia e a história como prática vivida. Esse contrassenso é observado pelo próprio Husserl sobre o sujeito: "A nós, a epoché retirounos precisamente este solo. E, na pura atitude correlativa que ela cria o mundo, $\mathrm{o}$ objetivo, torna-se ele próprio um particular subjetivo. Nesta atitude, o 'subjetivo' relativiza-se ainda mais de maneira paradoxal" (HUSSERL, 2012. p. 146). E em outra passagem: "O constituinte sujeito do mundo engole, por assim dizer, o mundo inteiro e, assim, também a si próprio. Que contrassenso!” (HUSSERL, 2012. p. 147).

Apesar de feitas essas observações, Husserl não toma uma direção oposta à sua teoria. O filósofo não visa obviamente negar a objetividade, mas pensar e estabelecer o que entende por objetivo como sendo o próprio subjetivo. Ou seja, considera como objetividade as relações dos eus-sujeitos com objetos, isto é, um objetivo em um subjetivo. Agrega-se ainda, como supracitado, a esta subjetividade a história e a linguística para caracterizar o mundo da vida. Como é notória, sua teoria não passará despercebida aos críticos como coloca Stein:

[...] Penso que a questão do mundo da vida deve ser colocada independente de uma análise da consciência. A única maneira de desligarmos a análise deste universo é encontrar um modo de distinguir a questão do mundo, ou a presença do ser humano no mundo, ou fazer uma distinção entre a maneira natural de ser (junto as coisas, junto a natureza) de uma outra maneira que não é natural. É preciso entender que desde sempre estamos ligados ao mundo a partir do qual definimos a natureza, o mundo natural [...] (STEIN, 2012, p.61).

Em uma interpretação do próprio Habermas sobre a definição do mundo da vida de Husserl, ele diz:

Ora, se prescindirmos dos conceitos da filosofia da consciência, que Husserl
utiliza para tratar da problemática do conceito mundo da vida poderemos
apresentar racionalmente o mundo da vida como uma reserva de padrões de
interpretação, organizados linguisticamente e transmitidos culturalmente.
(HABERMAS, 2012, p.254)

Assim dizendo, podemos entender o mundo da vida como essa "reserva de padrões de interpretação" e um plano de saber cultural que interpretamos. Absorvemos os conhecimentos culturais que foram formados e organizados pela linguagem e agora estão dispostos para serem transmitidos através da cultura.

Alfred Schütz, por sua vez, em uma abordagem parecida a Husserl, não se abstém de uma filosofia fenomenológica. Apesar disso, ele consegue desenhar com maior êxito uma fenomenologia alinhada à sociologia em seus estudos. Em uma visada ampla, a forma epistemológica do Schütz pouco difere da teoria de Husserl. A via possível da fenomenologia constitutiva da atitude natural (ou ontologia do mundo da vida) desenvolvida por Schütz (e Husserl), intercorre à consequência de um processo de redução. A redução é um conceito husserliano que explica o processo fenomenológico e, como aqui é de nosso interesse, o possível conhecimento pela experiência no mundo da vida cotidiano.

Através do conceito de duração, Schütz explica, por sua vez, as experiências e vivências que pode submeter-se o sujeito. Entretanto, isso decorre durante um fluxo desordenado e fragmentado de vivências. Por conseguinte, esses fragmentos desordenados da duração ainda estão em um plano pré-fenomênico (pré-consciente) e 
desvinculado da consciência (Cf. SCHÜTZ, 1973, p.60-65). Portanto, a duração estabelece apenas os fragmentos das experiências do sujeito. Para que o fenômeno seja apercebido ao sujeito é requerida uma configuração cognitiva.

Pela filosofia de Bergson, em seus conceitos de viver (duração) e pensar (espaço-temporal), Schütz redefine o conceito de espaço-temporal em um conceito de representações internas da consciência. Enquanto interno ao sujeito, ele projeta o plano (campo) de configuração para à duração. Por conseguinte, o espaço-temporal será como um mecanismo de configuração dos fragmentos de vivências ainda desordenados. Sendo assim, isso resulta em um terceiro nível, isto é, em certa tensão dos fragmentos desordenados da duração que Schütz denomina como tensão da consciência (Spannung Bewussteseins), ou seja, a partir daí o sujeito configura de forma ordenada essas experiências vividas (Erinnerung). Deste modo, a partir dos fundamentos na consciência, nós podemos falar em experiências. Contudo, o que foi cristalizado por esse processo de redução está apto para a transmissão pela linguagem.

Defendemos que a notória diferença entre Husserl e Schütz está, em grande medida, na proposta inicial dos autores. Schütz dedica todos seus esforços filosóficos também para resolver um problema social, ao passo que Husserl demanda esforços para uma profunda metodologia filosófica da fenomenologia. Nesta perspectiva corrobora Baxter,

Esta "ontologia do mundo da vida", deixada em grande parte inédita na morte de Husserl em 1938, fala mais diretamente das preocupações da fenomenologia transcendental do que das teorias sociais substantivas. Mas ofereceu um ponto de partida para o trabalho de Alfred Schutz, um teórico social e filósofo que foi muito influenciado por Max Weber e Husserl. Schutz, que estava mais interessado que Husserl na metodologia das ciências sociais e mais bem informado, também tentou descrever as estruturas gerais do mundo cotidiano e pré-científico de uma maneira que seria proveitosa para a teoria social. Schutz, seguindo Husserl, passou a chamar esse mundo de ação cotidiana e experimentar o "mundo da vida" (BAXTER, 2011.p. 21).

A filosofia de Husserl, de fato é mais complexa e sua contribuição para fenomenologia é sem dúvida, fundamental. No entanto, para nosso estudo e, por conseguinte, para a sustentação da proposta de Habermas, Schütz se insere de forma mais adequada, visto que sempre procurou uma saída da egologia encontrada em Husserl. Ainda no excerto abaixo é possível reconhecer a preocupação de Schütz:

O mundo da vida cotidiano é o cenário e também o objeto de nossas ações e interações. Nós temos que dominá-lo e transformá-lo de modo a ser possível concretizar os propósitos que buscamos realizar nele, entre nossos semelhantes [...] mundo, nesse sentido, é algo que precisamos modificar por nossas ações ou que modifica nossas ações [...] (SCHÜTZ, 1973, p.40).

Embora Habermas distinguirá seu conceito de mundo da vida de seus predecessores, ele claramente possui maior apreço pela abordagem de Schütz. Segundo Baxter: "A apresentação inicial de Habermas do conceito de mundo da vida acompanha em grande parte a análise de Schütz" (BAXTER, 2011. p. 21). Nesta medida, Habermas direciona critícas tanto à Husserl quanto à Schütz, apontando que seus conceitos de mundo da vida são culturalistas e unilarerais (Cf. HABERMAS, 2012. v. 2. p. 254). Sua 
proposta visa apresentar um conceito de mundo da vida não apenas culturalista, além de transpassar a compreensão de Husserl e Schütz sob um noção noção interpretativa e restrita ao saber cultural.

Desta feita, Habermas tem por objetivo a socilização e a integração social, inserindo neste âmbito critérios concernentes à solidariade entre membros de uma comunidade e de identidade de um indivíduo socializado. Por isso, ele percebe carência de explicações consistentes da vida social de indivíduos, restando somente uma explicação de intepretação de saber cultural. Assim, ele compreende um agir comunicativo que interpreta o mundo e permite à individuos formar, confirmar ou renovar sua indetidade e sua pertença a grupos sociais. (Cf. HABERMAS, 2012. v. 2. p. 255.)

\section{O MUNDO DA VIDA: APPROACH 2}

Conforme vimos, embora Habermas tece algumas críticas ao modelo schutziano, ele também ensossa algumas teses basilares da concepção de Schutz:

Essa reformulação "teórico-comunicativa" do conceito de mundo da vida de Schütz leva Habermas a novas revisões. Um objetivo principal é a noção de Schutz do "estoque de conhecimento", que Habermas interpreta como os "padrões culturais de interpretação, avaliação e expressão" nos quais os atores comunicativos confiam "para negociar uma definição comum de uma situação" e planos de ação compatíveis (BAXTER, 2011. p. 21).

$\mathrm{Na}$ mesma perspectiva, segue Fairthlough:

Todos têm seu próprio mundo da vida inquestionável na visão de Schutz. A visão de Habermas é de que um grupo tem seu próprio mundo da vida inquestionável e compartilhado. Novas situações necessitam de novas interpretações mútuas, que devem sempre resultar em pelo menos uma ligeira mudança no mundo da vida compartilhado, mas a maior parte do mundo da vida permanece inalterada como um recurso contínuo para futuras ações comunicativas (FAIRTLOUGH, 1991, p.550).

O estoque de conhecimento é o mesmo que Habermas aborda em sua reformulação teórica, quer dizer, padrões culturais de interpretação, avaliação e expressão. Apesar deste ponto de convergência, é uma reformulação em que a mudança certamente não passará despercebida. Como podemos observar, Habermas estabelece uma concepção de mundo da vida passível de mudanças possivelmente pequenas e talvez problemáticas, pois o mundo da vida está fixo em seu pano de fundo e só será questionado quando o pano que o emoldura sofrer um dano ou modificação.

O mundo da vida se edifica e é fixado por suas estruturas, as quais são, a cultura, a sociedade e a personalidade, que não são simples conceitos, mas conceitos teóricopráticos (veremos mais adiante). Essa estrutura composta por três partes permeará toda atividade [inter] subjetiva, o qual Habermas nunca cometeu o devaneio de lhe conceber como ilhado, mas sempre em relação com outro. Essa é uma tese permanente na teoria habermasiana, a saber, a consideração que não somos átomos isolados, mesmo no processo de realização pessoal.

É da inter-relação destas estruturas que podemos compreender melhor a proposta de mundo da vida de Habermas. Os indivíduos que necessariamente habitam um mundo da vida têm de carregarem por si o peso de suas próprias histórias de vida. Esse peso que os indivíduos carregam são aqueles de suas vivências, da vivência dos que o 
cercam (história, cultura, sociedade) e daqueles que o precederam. Neste sentido, o mundo da vida é também contextualista, pois, embora o indivíduo tenha capacidade de diálogo e construção normativa, está imerso no mundo da vida em que age e carrega seu peso (ou fardo) ao mesmo tempo.

Esse peso (ou fardo) que os indivíduos carregam, Habermas denomina de tema ou saber, isto é, quando lançamos no mundo um assunto designamos tema incorporado de saber. Destarte, é o pano de fundo do mundo da vida. Como é perceptível, o pano de fundo do mundo da vida é fixo, ou seja, neste patamar apenas pode-se dizer que se sabe, mas não o porquê se sabe. São noções prévias de um significado ainda não refletido, como mostra a passagem abaixo:

O mundo da vida forma o horizonte para situações de fala e constitui, ao mesmo tempo, a fonte das interpretações, reproduzindo-se somente através de ações comunicativas. O saber constitui o pano de fundo do mundo vida revela um aspecto que chama minha atenção: o caráter pré-predicativo e pré-categorial, que já despertara a curiosidade de Husserl, que fala num fundamento 'esquecido' do sentido de prática cotidiana e experiência do mundo. (HABERMAS, 2003. v. 1. p. 41)

Conforme excerto supracitado, o mundo da vida ainda está em um nível anterior à reflexão e não é de todo conscientes. Deste modo, quando lançamos mão de um dado saber, o tematizamos para a discussão e reflexão. O pano de fundo do mundo da vida é um saber que detemos em condições que não se auto-interpretam, e, por isso, carecem de uma interpretação vinculada ao agir comunicativo que é a única forma de compreendê-lo.

Neste sentido, as tematizações incorporadas de saber serão lançadas no mundo através de um processo necessariamente dialógico. Percebemos aqui a necessidade agraciada por Habermas de que a vida em grupo só pode ser constituída por intermédio do diálogo. E se, portanto, dispomos de uma razão comum a todos, também dispomos da capacidade e necessidade de diálogo por todos. Há, desta forma, a crença de que podemos construir um conjunto normativo guiado pela fala que definirá o modo de comportamento do grupo envolvido. Espera-se, desta forma, a estabilidade das relações justamente pelo fato da justificação ser uma construção.

Essa necessária comunicação dos participantes do mundo da vida proporciona a capacidade de reflexão daquilo que fora lançado como tema incorporado por saber e, a partir daí, sucede a decomposição deste saber. Por conseguinte, o elemento chave para a decomposição e entendimento destas tematizações do mundo da vida não é senão o agir comunicativo, ou seja, esse conceito elementar da teoria habermasiana que visa à persecução do entendimento e consenso entre os participantes.

Em resumo, o pano de fundo do mundo da vida é um saber e, enquanto saber, é pano de fundo para o mundo da vida, e este é pano de fundo para o agir comunicativo. Segundo Habermas: "Durante o agir comunicativo o mundo da vida nos envolve no modo de uma certeza imediata a partir da qual nós vivemos e falamos diretamente" (HABERMAS, 2003. v. 1. p. 41.). Ou seja, a partir da evidência disto que foi posto, os agentes do mundo da vida podem lançar mão de quaisquer saberes que concernem ao seu mundo.

\section{AproximaÇão aos três mundos de PopPer}

A teoria dos três mundos de Popper é uma abordagem que concerne a sua epistemologia, e não somente, como ele diz, uma referência à realidade (Cf. POPPER, 
1988, p.23). Os mundos de Popper encarnam uma teoria biológica e ontológica em sua formulação, de modo que quando o Austríaco formula, o faz sob considerações da teoria da evolução proposta por Charles Darwin.

De modo geral, o mundo 1 (M1) representa o mundo objetivo, ou seja, tem-se aqui toda a estrutura objetiva de um mundo, mesmo sem levar em consideração o surgimento dos seres vivos. Seguindo o caráter evolutivo, o mundo 2 (M2) refere-se ao intelecto, à emoção e ao inconsciente, portanto, nesta fase evolutiva temos o ser humano subjetivo com suas características comuns. Sendo assim, o mundo 3 (M3) carrega toda a atividade humana produzida, ou seja, o mundo em que podemos conceber as criações do espírito (intelecto, mente), por exemplo, as intelectuais, as artísticas, etc.

[...] Nossa realidade consiste, pois, de acordo com esta terminologia, em três mundos ligados entre si e de algum modo interdependentes, e que em parte se interpenetram. (Neste contexto, a palavra 'mundo' não significa evidentemente universo ou cosmo, mas sim partes deste). Estes três mundos são: o mundo físico, mundo 1, dos corpos e dos estados, fenômenos e forças físicas; o mundo psíquico, mundo 2, das emoções e dos processos psíquicos inconscientes; e o mundo 3, dos produtos intelectuais [...] (POPPER, 1988. p. 22).

Segundo Popper, o homem é formado por determinações que lhe são externas (e em parte interna), uma decorrência da seleção natural. A natureza do M2 é fruto desta seleção natural, a qual descreve o ser humano. Porquanto, é ele que representa o M2 dotado de emoções, processos psíquicos e inconsciente. O M3 de Popper se interrelaciona com os demais, mas contempla um caráter autônomo perante os mundos M1 e M2. O M3 é somente produto das atividades do espírito. Para tornar mais clara a relação: o M1 e M2 se relacionam de forma direta; o M1 e M3 se relacionam de forma indireta, mas necessariamente mediados pelo M2. O M2 e M3 se relacionam, porém, o M3 adquire completa autonomia.

Ao que indica, Habemas se preocupa com as estruturas e construções do M3, pois é neste mundo que se fundamenta todo produto intelectual, inclusive a linguística. Portanto, mesmo que a linguística considerada por Popper como produto do espírito tenha papel atuante em M1 e M2, ela é por excelência objeto do M3. Habermas se agrada com a introdução de um terceiro mundo, pois a criação de um terceiro mundo foge, por exemplo, de concepções materialistas, em que somente há uma relação ator/mundo objetivo (ator/M1) ou de uma relação unilateral idealista subjetivista (ator/M2) (HABERMAS, 2012, p.154-5).

A principal crítica de Habermas ao modelo popperiano de M3 é direcionada aos aspectos de um determinismo da seleção natural e, por conseguinte, não possibilitar estabelecer condições de interpretação e produção de tipos diferentes, tais como: sistemas de normas, sistemas sociais, etc. Ou seja, essas produções que demandam complexidade e abstração ou uma inter-relação entre indivíduos são descabidas para um mundo autônomo de Popper. Isso já havia sido percebido por Ian. G. Jarvie, como pontua Rocha:

Por isso Habermas recorre à concepção da teoria de três mundos de Popper, na versão de Ian G. Jarvie, encontrando aí um significado especial para a sua teoria da ação comunicativa. [...] O intento de Jarvie, principalmente de transpor a teoria dos três mundos de Popper da 'teoria do conhecimento' para 'teoria da ação' representa um interesse acrescido para Habermas [...] (ROCHA, 2008, p.144).

Desta forma, Habermas passa de um conceito "mundológico" para uma análise do mundo na perspectiva da teoria da comunicação: 
Em primeiro lugar gostaria de substituir o conceito ontológico de mundo, ligado à teoria da constituição e adotar o par conceitual 'mundo' e 'mundo da vida'. São os próprios sujeitos socialmente coletivizados que, ao tomar parte em processos interpretativos cooperativos, empregam implicitamente o conceito de mundo (HABERMAS, 2012, p.159).

Como Habermas aponta, grande parte dos filósofos se dedicaram ao estudo de um agir em bases ontológicas ou metafísicas. Por sua vez, Habermas fundamenta o agir em uma teoria comunicativa. Para isso, o alemão irá dividir o mundo em três partes e reformular a teoria de Popper. O conceito de três mundos de Habermas - o objetivo, o social e o subjetivo - são de inestimável valor para a ação, visto que são formas em que o agente se localiza e orienta-se em um "mundo inter-activo".

Porquanto ter essas noções formais de ação comunicativa é de imensurável importância para nosso empreendimento, pois, no mundo da vida, nos orientamos por essas noções e de certa maneira elas estão presentes nas estruturas do mundo da vida. $\mathrm{O}$ sujeito, no mundo da vida, não age guiado por um imperativo sugere o idealista e nem por uma visão estratégia do mundo, como queria o teórico do agir estratégico. O sujeito age perpassando uma relação tríplice, o objetivo, o social e o subjetivo, na qual ele se constitui como agente. Na passagem abaixo temos uma definição dos três mundos enquanto formas nos atos de fala:

A análise dos modos de utilização da linguagem permite esclarecer o que significa o fato de um falante, ao realizar um ato de fala padrão, entabular uma relação pragmática: - Como algo no mundo objetivo (enquanto totalidade das entidades sobre as quais são possíveis os enunciados verdadeiros); - Com algo zno mundo social (enquanto totalidade das relações interpessoais reguladas legitimamente); - Com algo no mundo subjetivo (enquanto totalidade das vivências às quais o falante tem acesso privilegiado e que ele pode manifestar de modo veraz diante de um público (HABERMAS, 2012. p. 220).

Nota-se, todavia, que há uma distinção entre formas de mundos e estruturas. Portanto, é perceptível a diferenciação no emprego de tais noções. Porquanto, o leitor atento já pode identificar que as estruturas podem ser entendidas como derivações das formas, embora diferenciem das formas como referências à intersubjetividade. Abaixo Habermas será claro:

Isso porque os que agem comunicativamente sempre no horizonte de seu mundo da vida, não conseguido desvencilhar dele. Enquanto interpretes e seguindo de seus atos de fala, eles mesmos constituem parte integrante do mundo da vida; mesmo assim não podem referir a algo no "mundo da vida" como costumam se referir a fatos, normas ou vivências. Porquanto as estruturas do mundo da vida fixam as formas da intersubjetividade do entendimento possível [...] (HABERMAS, 2012. v. 2. p. 231).

Como foi dito há pouco as três formas capacitam o indivíduo para localizar-se e orientar-se numa ação. Desta forma, podemos entabular qualquer ação numa dessas categorias. Não obstante, estamos sempre fazendo referências a estas. Podemos fazer referência a algo no mundo objetivo, a algo no mundo social ao seguir certa normatividade de um contexto social, ou ainda, enquanto fazemos referência ao mundo subjetivo, com isto, tendo na situação da fala do indivíduo um elevado grau de certeza do enunciado (Cf. (HABERMAS, 2012, v.2, p.220).

Contudo, o conceito de formas (três mundos) não é análogo ao conceito do mundo da vida, pois o mundo da vida, como vimos até aqui, é um saber fixo não refletido. O mundo da vida carece de interpretação, como vimos na definição de seu 
pano de fundo. Como alinhar as formas que nos orientamos em uma ação comunicativa com a intersubjetividade que dispomos em um mundo da vida? Para isso, Habermas apresenta as estruturas do mundo da vida. Se de um lado, até aqui, tínhamos apenas as formas do entendimento do agir comunicativo, as estruturas do mundo da vida fixam as formas da intersubjetividade que proporciona aos falantes e ouvintes capacidade de entendimento sobre o mundo da vida, tanto em nível objetivo (indireto-simbólico), quanto em um nível abstrato de entendimento intersubjetivo.

Em uma perspectiva intramundana, sob a cultura e a linguística, não conseguimos nos desvencilhar do mundo da vida e adotar uma perspectiva extramundana. Vejamos a passagem:

Ao realizar um ato de fala, os participantes da comunicação se movem no interior de sua linguagem, porém de tal modo que não conseguem encarar uma exteriorização atual como algo "intersubjetivo" da mesma maneira como que eles experimentam um acontecimento como algo objetivo, como eles enfrentam uma expectativa de comportamento normativo ou como vivenciam/atribuem um sentimento e um desejo como algo subjetivo (HABERMAS, 2012, v.2, p.229).

Mesmo que seja possível fazer exteriorizações pelas formas do entendimento, contudo, enquanto mundo da vida carecemos de uma posição extramundana para compreensão do próprio mundo da vida. Isto só pode ser solucionado com a intersubjetividade, ou melhor, com as estruturas do mundo da vida. Vejamos a seguinte passagem: "Porquanto as estruturas do mundo da vida fixam as formas da intersubjetividade. Graças a elas, os participantes da comunicação conseguem assumir uma posição extramundana ao que é intramundano, sobre o qual eles pretendem se entender" (HABERMAS, 2012, v.2, p.231). Ao menos pelo aspecto funcional podemos entender o mundo da vida, ou seja, pelo funcionamento de suas estruturas simbólicas. É graças a intersubjetividade e o agir comunicativo que podemos ter um entendimento e uma interpretação de mundo possível dentro de um limite circunscrito às estruturas do mundo da vida, ou seja, as já mencionadas estruturas que são: cultura, sociedade e personalidade.

A cultura constitui o estoque ou reserva do saber, do qual os participantes da comunicação extraem interpretações no momento em que tentam se entender como algo no mundo. Defino sociedade por meio das ordens legitimas pelas quais os participantes da comunicação regulam sua pertença a grupos sociais, assegurando a solidariedade. Interpreto a personalidade como conjunto de competências que tornam um sujeito capaz de fala e ação-portanto, que colocam em condições de participar de processos de entendimento, permitindo-lhe afirmar sua identidade [...] (HABERMAS, 2012. v. 2. p. 252)

Habermas não está abordando referências diretas a algo no mundo, mas a abordagem do agir comunicativo se atém a intersubjetividade da linguagem, com isto é possível obter entendimento sobre algo no mundo e ainda consenso intersubjetivo, ou seja, em um nível mais abstrato podemos concordar sobre a validade de nossas conclusões tomadas intersubjetivamente a despeito de algo no mundo.

Ao introduzir o conceito de mundo da vida, Habermas enfatiza que necessariamente estamos nele e nos encontramos uns com os outros utilizando-se da linguagem como meio em um horizonte. A noção de horizonte, Habermas toma emprestado de Husserl para significar aspectos importantes do agir comunicativo (Cf. HABERMAS, 2012. v. 2. p. 226.). Primeiro, o horizonte serve de imagem de mudança, ou seja, no agir comunicativo dentro do mundo da vida utilizamos de diversos temas e o 
horizonte acompanha essas mudanças. Outro aspecto é o da imagem de um horizonte não limitado, ou seja, quando agimos por temas lançados, o horizonte se expande ao fazer ressignificações e reproduções, porém, estando o indivíduo em seu mundo da vida, permanecerá desde sempre e para sempre (HABERMAS, 2012. v. 2. p. 220).

As mudanças no mundo da vida se dão no interior das estruturas. Assim sendo, surge possivelmente na mente do leitor um paradoxo: tendo em vista que o mundo da vida foi caracterizado pela sua imutabilidade, como falar, então, em mudança? $\mathrm{O}$ paradoxo é, pois, que o mundo da vida é imutável na sua integralidade, mas mutável, por sua vez, na tematização de suas estruturas. Em realidade, não é surpresa o pretenso paradoxo no mundo da vida. Entretanto o mundo da vida não pode ser encarado como um simples conceito binário. Porquanto, ele representa uma esfera da sociedade, de um indivíduo inserido em meio social e, desta forma, necessita de uma esquematização por deveras teórica.

O mundo da vida é inquestionável em seu pano de fundo ou na cultura como vimos no seu aspecto objetivo de mundo. Contudo, existe um locus no mundo da vida nomeado de horizonte em que podemos lançar mão de pressuposições, afirmações, etc. Nesse local, o horizonte se desloca conforme a necessidade. Mesmo assim, enfatizamos que um indivíduo não se desvencilha de seu mundo da vida.

De fato, em princípio, as estruturas de mundo da vida mostram-se imóveis e inquestionáveis. Entretanto, conforme os membros agem comunicativamente as estruturas do mundo da vida sofrem modificações e estas modificações culminam em reproduções no mundo da vida. A esses processos de reprodução são designados cada um a sua estrutura correspondente. Vejamos a passagem:

O processo de reprodução consegue ligar situações novas aos estados do mundo da vida já existentes, seja na dimensão semântica dos significados e dos conteúdos (da tradição cultural), seja nas dimensões do espaço social (de grupos socialmente integrados), seja no tempo histórico (das gerações que se sucederam). A esses processos de reprodução cultural, de integração social e de socialização correspondem, enquanto componentes estruturais do mundo da vida, a cultura, a sociedade e a pessoa (HABERMAS, 2012. v. 2. p. 252).

Por exemplo, um indivíduo pode se questionar sobre um determinado saber $X$ e lança-lo para discussão; a esse saber em movimento colocamos na conta da reprodução cultural. Um indivíduo pode lançar dúvida sobre certo modo normativo $Y$ no seu meio social; a este tipo de abalo estrutural culmina em reprodução de integração social. Um indivíduo pode duvidar de uma certeza $Z$ em sua identidade como pessoa de pertença social; a esse movimento colocamos na conta da socialização. Esses processos dentro do mundo da vida não são unilaterais (como a crítica de Habermas à Husserl e Schütz). Pelo contrário, eles estão entrelaçados sempre em pelo menos duas estruturas. Poderia um agente tematizar algo $X$ do seu saber cultural e ao mesmo tempo interferir à personalidade sobre suas certezas de identidade. Pode-se também dizer que não tem uma validade do ponto de vista da estrutura da sociedade, pois naquele meio social em que ele lançou $X$, ele não é valido.

Habermas distingue a reprodução estrutural de que falamos até agora em duas: a simbólica e a material (Cf. HABERMAS, 2012. v. 2. p.223). Tomamos a reprodução simbólica, pois ela é a responsável pelas situações da fala, ou seja, é sobre a reprodução simbólica que se debruça a busca por entendimento intersubjetivo sobre algo no mundo. A despeito da reprodução material ela serve de substrato na acoplagem do que foi tido como válido no âmbito simbólico em alusão à matéria. 


\section{A RACIONAlizaÇÃo do MUNDO DA VIDA}

A existência de um perfil de sociedade idealizada em sua homogeneidade nos remete às sociedades tradicionais ou arcaicas. Em linhas gerais, elas são sociedades representadas pela figura de um soberano e pelo sagrado, sendo que o sagrado se mantém como fonte de moralidade da comunidade. Para exemplificação, essas sociedades entraram em conflito na medida em que seus pertencentes questionaram sobre o que era compreendido como convicção. Porquanto, quando surgem os conflitos, a racionalidade se manifesta com naturalidade substancial. Desta forma, o sagrado e o inquestionável foram sendo diluídos em formas de linguagem, ou seja, aquilo que anteriormente era uma sociedade homogênea compreendida pela assimilação da ordenação de um soberano, foi sofrendo um processo de mutação para o entendimento linguístico. E o entendimento linguístico só pode ter êxito por uma evolução cognitiva, isto é, pelo desenvolvimento da razão e da linguagem (Cf. HABERMAS, 2012. v. 2. p.263).

De acordo com Habermas a racionalização do mundo da vida ocorre nas estruturas. Vejamos a seguinte passagem:

Os pontos de referência históricos, aduzidos por Mead e Durkheim para uma racionalização do mundo da vida, podem ser sistematizados sob três pontos de vista distintos, a saber: o da diferenciação estrutural do mundo da vida (a), o da separação entre forma e conteúdo (b) e o da reflexibilização de reprodução simbólica (c) (HABERMAS, 2012. v. 2. p. 264).

De fato, a racionalização do mundo da vida decorre de conflitos estruturais no mundo da vida. Quando em conflito, as estruturas necessitam ser racionalizadas, quer dizer, os participantes do mundo da vida por um imperativo sentem a necessidade de orientar-se pelo entendimento, já que não há mais um engate social não-refletido que dê conta da estabilidade das relações.

$\mathrm{Na}$ relação cultura/sociedade, a cultura e o conjunto de instituições se separam da cosmovisão mítica. Na relação sociedade/personalidade, ampliam-se as possibilidades e produzem-se relações interpessoais. Na relação cultura/personalidade, as tradições, outrora alicerçadas na visão mítica, apoiam-se na capacidade de indivíduos produzirem transformações e reformulações na tradição.

A despeito da separação da forma e conteúdo no plano cultural, os indivíduos afastam-se da tradição (e cosmovisão) estabelecendo uma cortina de elementos formais, tais como: procedimentos formais, valores fundamentais, linguística, abstrações em geral, etc. No nível sociedade, os indivíduos abandonam seus princípios gerais e nas sociedades modernas empreendem as formas abstratas da moral e das normas. No âmbito da personalidade, os indivíduos desconectam cada vez mais do saber cultural e assumem posições contingenciais de modo a aumentar suas capacidades em sociedade.

O último ponto de vista da racionalização do mundo da vida é o da flexibilização da reprodução simbólica. Com o advento das sociedades modernas, a especificação funcional e o alargamento da reprodução das estruturas do mundo da vida, permitiram ao ser humano moderno estabelecer uma vasta lista de competências especializadas (jurista, médico, físico), isto é, uma tendência natural e observada nas sociedades modernas.

Nesta linha, em sua obra, Max Weber fundamenta um estudo da sociedade seguindo um desenvolvimento histórico que podemos assimilar ao intitulado "racionalismo ocidental". Habermas serviu-se dos referidos estudos para fundamentar 
aquilo que entendeu como racionalização do mundo da vida. Weber compreende um mundo em progressiva racionalização, ao passo que pressupõe o uso de uma razão meramente instrumental ou estratégica. Com isto, podemos compreender que a partir de sociedades tradicionais, a racionalização do uso de meios estratégicos trouxe a formação de uma cadeia de instrumentalização da razão em diversas ramificações que dela procederam. Exemplo: a medicina; a psicologia; a arquitetura (com uso da razão de suas formas com vistas ao belo e do uso racional de espaços); a música clássica, e classificação de seguimentos harmônicos codificados e padronizados (facilmente percebido em concertos clássicos).

Apesar de Habermas e Weber estarem de acordo sobre a racionalização do mundo, Habermas percebe em Weber uma sociedade meramente instrumental ou como Parsons e Kent fazem a analogia, uma “Iron Cage”. Analisam Tweedy e Hunt:

A tese de Weber de que a racionalização progressiva da sociedade no curso da modernidade engendrou um aumento paradoxal da autonomia e da perda de liberdade, à medida que o subsistema instrumentalmente racional de estado e economia adquiria um papel cada vez maior na socialização dos indivíduos (HUNT; TWEEDY, 1994, 293).

Nesse sentido, as sociedades são pensadas de forma pessimista. A racionalização assume contornos com vistas a minar a moralidade, sendo que a economia e o poder estatal, podem tramitar abertamente liberando uma excessiva sistematização nas condutas individuais. Como pontua Baxter, a racionalização apenas instrumental deixa a questão incompleta ou seletiva aos meios (dinheiro e poder).

Weber não tinha um conceito de ação comunicativa e racionalidade comunicativa. Ambos os recursos da abordagem de Weber, afirma Habermas, levou Weber a perder alguns dos sentidos em que as sociedades modernas foram racionalizadas e passou sobre a questão de saber se o projeto de racionalização, como realmente tem desdobrado, foi seletivo ou incompleto (BAXTER, 2011, p.28).

A preocupação de Habermas em fundamentar sua teoria social em sociedades primitivas não é mera opulência desnecessária, mas uma necessidade de fundamentar a sua filosofia no ser humano histórico e que se mantém em uma evolução cognitiva e social. Partindo das sociedades tribais apresentadas por Habermas, depreendemos que a homogeneidade dessas sociedades era predominante.

Essas sociedades tribais mantinham relações de parentesco e mínima hierarquização. Conforme as mudanças - racionalização - estruturais do mundo da vida foram percorrendo a história, essas sociedades mudaram para estratificadas, ou seja, uma sociedade já com um nível de sistematização minimamente hierarquizada (como no feudalismo europeu). Ainda, antes dos sistemas modernos, as sociedades eram sistematizadas em um nível de reificação, ou seja, entre os pertencentes do mundo da vida, em um nível horizontal de relacionamento, adquiriam formas de tratamento com vistas a fins sistêmicos. Por seu turno, um completo desalinhamento que culminará em problemas formais, por exemplo, da moralidade e do direito. E a partir dos crescentes subsistemas que emergem do mundo da vida torna-se patente a necessidade de uma legitimação dessas fontes e meios sistêmicos.

A partir da racionalização, a sociedade torna-se complexa, plural e burocrática. Nesta esteira, Habermas separa a sociedade moderna entre mundo da vida e sistema, a saber:

A separação entre sistema e mundo da vida reflete-se no interior dos mundos da vida modernos, inicialmente como reificação. Sistema da sociedade explode 
definitivamente o horizonte do mundo da vida, subtraindo-se à pré-compreensão prática comunicativa cotidiana e tornando-se, a partir de então, acessível apenas ao saber contraintuitivo das ciências sociais que começam a surgir no século XVIII (HABERMAS, 2012. v. 2. p. 312)

A sociedade definitivamente explode em seu horizonte do mundo da vida, como bem coloca Habermas. A necessidade por uma racionalização é natural e independe de desejo ou vontade. A evolução, proposta por Habermas, é consequência de cooperação social de indivíduos que provocam a liberação do potencial de racionalidade do agir comunicativo (Cf. HABERMAS, 2012. v. 2. p.313).

\section{OS MEIOS DE DIREÇÃO}

Em sociedades primitivas, a criação de padrões de valores e normas acompanhava a conduta de indivíduos possuidores de prestígio e influência. Por conseguinte, é por seu prestígio que podem influenciar (e vice-versa) outros a seguirem seus padrões de conduta. Nas sociedades modernas é descabida essa teoria de "mimetismo", sendo que se adquire um padrão geral para ações, o que Habermas denomina, em uma linguagem parsoniana, generalização de valores.

O prestígio e a influência são formadores da disposição de obedecer e, através deles, Habermas aborda os meios de direção. Segundo Habermas, "já conhecemos o prestígio e a influência, geradores primitivos da disposição de obedecer. Ora, a formação dos meios se inicia a partir deles" (HABERMAS, 2012. v. 2 p. 327). Já nas sociedades primitivas o prestígio e a influência orientavam como meios que interferiam no direcionamento da conduta. $\mathrm{O}$ mesmo acontece nas sociedades modernas, porém, com o dinheiro e o poder como meios de direção.

No mundo das ações agimos com fins à persecução de entendimento e consenso, mas, também e ao mesmo tempo, temos a disposição ações mediadas pelos meios de direção. Quando orientados pelo meio dinheiro, adotamos uma postura estratégica de cálculo quase sempre com fins para a retenção financeira. Como estamos no nível de relações interpessoais no mundo da vida, o dinheiro requer institucionalização financeira (na estrutura sociedade), por conseguinte, a "ancoragem" no mundo da vida.

O poder é um meio de direção e deve ser também legalmente institucionalizado e, por sua característica, possui o apoio da força coativa. Contudo, o poder deve ser legitimado e isso significa que seu exercício permanece conectado à ideia de reconhecimento de reivindicações de validade normativa. De fato, o poder requer ancoragem institucional no mundo da vida, pois se pretende que o poder seja estatuído através de pressupostos comunicativos mais abstratos, formais e problemáticos do que a monetarização (no mundo da vida). Assim sendo, a ancoragem do meio poder é mais exigente do que ancoragem do meio dinheiro o qual não precisa de legitimação além de sua institucionalização legal.

O motivo dessa assimetria na "ancoragem normativa", segundo Habermas, diz respeito à diferença nas "situações-padrão" entre os medium. No caso do dinheiro, as partes na "relação de troca ideal-típica" se encontram em termos iguais. Nenhum dos dois tem poder de comando sobre o outro e nem pode insistir na participação do outro. No caso do poder, por outro lado, a situação padrão é aquela em que uma parte comanda e dispõe dos meios necessários para garantir a conformidade. Parsons vê que, para que o poder sirva como um meio estável, ele deve ser direcionado a objetivos coletivos. E, no entanto, Habermas observa, se o detentor do poder é capaz de definir "quais objetivos serão considerados 
coletivos", essa determinação deve ser contestável por aqueles que estão sujeitos ao poder (BAXTER, 2011, p.42).

Ainda segundo Baxter, embora haja diferença entre os meios de direção, Habermas confia na semelhança geral entre dinheiro e poder no que diz respeito a sua ancoragem no mundo da vida. A primeira semelhança é que tanto dinheiro como o poder precisam ser legalmente institucionalizados para que se manifestem como um medium com base segura de confiança. A outra semelhança diz respeito à situação padrão para a operação de cada médium. Ambos os casos, a situação dos meios de direção envolve uma interação mais ou menos calculada e orientada para o sucesso. Desta forma, os atores podem contornar o processo de alcançar o entendimento. Ainda se diga que, embora o poder, em última análise, remeta a um consenso legitimador, não significa que a motivação para o cumprimento, em casos particulares do exercício do poder, seja de fato "racional". O sistema administrativo, como um todo, deve ser legítimo para que o poder seja um meio estável. Entretanto, o exercício real do poder, no entanto, geralmente opera sem justificativa normativa detalhada a ser dada ou solicitada (Cf. BAXTER, 2011, p.43).

Habermas analisa ainda o desacoplamento do sistema e do mundo da vida como um processo de segunda ordem, ou seja, evidencia a diferenciação dos sistemas econômicos e administrativos e a diferenciação dos componentes estruturais do mundo da vida. Isso ocorre pela caracterização Estado e economia como "sistemas", os quais, enquanto sistemas, são diferenciados em seus “ambientes” (Cf. BAXTER, 2011, p.46).

\section{A COLONIZAÇÃo dO MUNDO DA VIDA}

Como foi dito, a forma linguística representada no agir comunicativo não está imune aos meios de direção. A força de potencial racional presente no agir comunicativo, ou seja, nas relações mais humanas que visam uma progressiva racionalização através da cooperação intersubjetiva e isentas de uma perspectiva de orientação teleológica, pode estar padecendo de um envoltório sistêmico no mundo da vida. Segundo Habermas:

À medida que simplificam a comunicação linguística e a substituem por uma generalização simbólica de prejuízos e ressarcimentos, o contexto do mundo da vida, em que os processos de entendimento estão inseridos, é desvalorizado em benefício de interações controladas por meios, e, como consequência, a coordenação das ações não necessita mais do mundo da vida (HABERMAS, 2012. v. 2. p. 331-330).

$\mathrm{Na}$ medida em que há uma clara separação entre sistema e mundo da vida, como vimos anteriormente, poderíamos entender que esta disjunção não pode ser mais problematizada. Mas o que segue é que os meios de direção interferem no mundo da vida e podem causar dano. Essa interferência no mundo da vida por meios sistêmicos, Habermas denomina de mediatização do mundo da vida. Apesar disso, não se pode ter uma compreensão interna no mundo da vida acerca da interferência destes mecanismos sistêmicos. Habermas clarifica que os meios sistêmicos são um "corpo estranho" no interior do mundo da vida e que se manifestam nas condições formais do agir comunicativo (Cf. HABERMAS, 2012. v. 2. p. 336-7).

Desta forma, o problema desse desafogo no mundo da vida culminará em uma progressiva agressão à linguagem e ao agir comunicativo. Ou seja, a coordenação das ações orientadas pelo entendimento é substituída por um modo de coordenação de ação que não consagram o potencial de racionalidade do mundo da vida, mas sim, objetivam 
a coordenação da ação por meios que violam a "pureza" do mundo da vida. Essas influências sistêmicas agridem as estruturas do mundo da vida pelas condições formais do agir comunicativo:

A violência estrutural do mundo da vida é exercida por meio de restrições sistemáticas à comunicação; e ela está ancorada de tal forma nas condições formais do agir comunicativo, que os participantes não podem mais distinguir claramente os três mundos entre si, a saber o mundo objetivo, o social e o subjetivo (HABERMAS, 2012. v. 2. p. 337).

Seguindo as linhas teóricas de Horkheimer e Adorno no que concerne à conexão entre agir estratégico e sistema, Habermas considera que o capitalismo está associado com a generalização de uma racionalidade estratégica que tem invadido áreas da vida social. Do ponto de vista de Marx, e ainda Foucault, Habermas analisa a sociedade moderna em estados patológicos que inibem a socialização. Estes efeitos estão associados à reificação, alienação, vigilância e normalização. Este é um indicativo das patologias sociais da colonização do mundo da vida (HUNT; TWEEDY, 1994, p.289290).

Desta feita, a partir do momento em que o consenso não pode ser mais garantido e, por conseguinte, a reprodução simbólica cessa, o mundo da vida passa de uma mediatização para uma colonização. Assim,

[...] no final de tudo, mecanismos sistêmicos reprimem formas da integração social, também em áreas nas quais a coordenação consensual da ação não pode ser substituída, ou seja, nas quais está em jogo a reprodução simbólica do mundo da vida. A partir daí, a mediatização se transforma em colonização (HABERMAS, 2012. v. 2. p. 355).

$\mathrm{O}$ mundo da vida carrega o fardo daquilo que infere dentro dele, assim sendo, um mundo da vida racionalizado e complexo podem conduzir sistemas a interferirem no próprio mundo da vida. Portanto, este é o imbróglio paradoxal no qual a necessidade corrente de uma racionalização é necessária e inevitável na teoria da evolução social de Habermas e simultaneamente leva a persistente colonização que se volta ao mundo da vida. Nas palavras de Habermas: "O mundo da vida racionalizado possibilita o surgimento e o crescimento de certos subsistemas, cujos imperativos, ao se tornarem autônomos, ricocheteiam de modo destrutivo sobre o próprio mundo da vida" (HABERMAS, 2012. v. 2. p. 336).

\section{O DIREITO}

O sistema administrativo e econômicos, dirigidos pelo poder e dinheiro respectivamente, assolam o mundo da vida, entravando a comunicação desde as formas do agir comunicativo até o abalo das estruturas do mundo da vida e, consequentemente, reprimem a reprodução simbólica. Tendo isto em vista, Deflem adverte:

O direito é a instituição que estabelece a "ancoragem" normativa dos meios de direção dinheiro e poder no mundo da vida. Em outras palavras, os sistemas podem operar independentemente do mundo da vida apenas quando são recuperados ao mundo da vida por meio da legalização de seus respectivos meios de comunicação (DEFLEM, 1996, p.6).

Com a inserção desse complexo sistema de direito que Habermas aborda de forma singular, é requerido que essa "ancoragem" regule, ou seja, estabeleça leis que 
mediem os subsistemas administrativo e econômico, e desta forma, podemos pleitear a incognita que sucita sobre a legitimação.

O direito em Habermas nos coloca em uma possível aporia entre as obras Teoria do agir comunicativo (1981) e Direito e Democracia: Entre Facticidade e Validade (1992). Duas obras que abordam o direito, no entanto é somente em Entre Facticidade e Validade que temos uma mais esquadrinhada esquematização de Habermas e uma possível solução ao que pôde ter ficado ainda obscuro na Teoria do agir comunicativo (TAC).

O direito, consoante Junior, na primeira obra (1981) pode ser dividido em duas acepções. Primeiramente, o direito é assegurado como meio organizador (e controlador) dos sistemas Estado e economia que segundo Junior, Habermas refere-se às maiorias das matérias tocantes ao direito econômico, empresarial, comercial e administrativo (JUNIOR, 2005, p.170). O direito como meio adquire sua legitimação na própria criação de atos normativos. Assim sendo, apenas a aplicação procedimental seria suficiente para a fundamentação.

A segunda acepção endossa que o direito deve ser compreendido como uma instituição. Neste sentido Habermas procura assegurar a legitimidade não apenas no procedimento formal do direito como meio, mas procura na aplicação procedimental formal combinado ao direito material, uma possível legitimação. O direito como instituição abrange maior proximidade com indivíduos em um nível moral. No direito como instituição, aventamos uma necessidade de uma conexão com o mundo da vida e, portanto, é no mundo da vida, de modo intersubjetivo, que se pode assegurar sua legitimidade.

Contudo, as críticas ao modelo de Habermas (na TAC) irão recair sobre o direito como meio. Segundo Baxter:

[...] Mas por causa de sua conexão com os meios dinheiro e poder, o direito como meio é "tecnicizado e desmoralizado" e pode ser avaliado de forma não substantiva, mas apenas de acordo com sua funcionalidade ou sucesso instrumental. Além disso, no que diz respeito à tese da juridificação, Habermas argumenta que o direito, como um meio de direção, tem sido um instrumento do projeto de estado do welfare-state que domesticando "as relações modernas de poder e dependência que surgiram com o empreediemnto capitalista [e] o aparato burocrático de dominação". Sua classificação do direito como um meio de direção neste projeto, também, faz parte de seu diagnóstico de que o intervencionismo do welfare-state tende a interromper a comunicação de domínios estruturados e organizados informalmente que regulam (BAXTER, 2011. p. 57).

Apesar de Habermas apontar para o problema das patologias do mundo da vida que decorrem da tese de juridificação, ele mantem o direito como meio, de modo que sua legitimação é extraída do próprio procedimento, ou seja, não observamos uma ancoragem no mundo da vida do direito como os outros dois meios de direção. Não obstante, seguramente Habermas sempre esteve preocupado com a legitimação e validade do direito, de modo que, já na $T A C$, afirma que "as leis necessitam de reconhecimento intersubjetivo dos cidadãos, ou seja, tem de ser legitimadas como justas" (HABERMAS, 2012. v. 2. p. 339).

As Tanner Lectures de Habermas, proferidas em 1986, foi um prelúdio com a intenção de dar continuidade ou resolver o problema do direito como meio apresentado na obra TAC. Nesses textos Habermas procura encontrar uma maneira de dar sustentação à tese da impossibilidade de extrair a legitimidade da legalidade. Desta forma, usa do positivismo de Weber para sustentar seu discurso que concerne à 
legitimação.

Por seu turno, Weber, representante do direito positivo formal, desenvolveu sua tese embasada em uma razão instrumental que objetiva fins e, por conseguinte, esses fins são de valores materiais. Com isto, Weber fundamenta um nível de direito absolutamente racional e que extraí da sua forma, ou seja, na sua própria legalidade e na consecução de processos formais estabelecidos, a sua legitimidade. Desta forma, há em Weber uma completa cisão entre moralidade e direito. Assim sendo, o direito formal paira sobre os sujeitos morais. Por sua vez, o próprio Habermas sugere uma hipótese para uma legitimação por meio da legalidade:

[...] Então pode-se adotar a seguinte hipótese: A legitimidade pode ser obtida através da legalidade na medida em que os processos para a produção de normas jurídicas são no sentido de uma razão prático-moral procedimental. A legitimidade da legalidade resulta do entrelaçamento de processo jurídicos e uma argumentação moral que obedeça a sua própria racionalidade procedimental (HABERMAS, 2003. v. 2. p. 203).

Nas Tanner Lectures, Habermas mostra ainda um entrelaçamento com a moral quando aponta para a cisão entre moral e direito de Weber. Podemos conferir nas críticas ao modelo do direito formal alheio aos indivíduos e que adquire validade meramente por sua racionalidade processual. Sendo assim, o problema da legitimação do direito, ao menos em Habermas, é um problema intrinsecamente moral, ou seja, do mundo da vida. Porquanto, a última citação expõe uma resposta à pergunta: Como é possível a legitimidade da legalidade? A resposta de Habermas atravessa a moral: "[...] resulta do entrelaçamento de processos jurídicos e uma argumentação moral que obedeça a sua própria racionalidade procedimental" (HABERMAS, 2003. v. 2. p. 203).

Da passagem das Tanner Lectures (1986) para entre Facticidade e Validade (1991), o pensamento de Habermas prosseguiu em sentido à legitimação. Contudo, Habermas já apontava para uma saída com entrelaçamento entre moral e direito em 1986, visto que em caso de fraqueza moral de sujeitos, o direito tomaria a responsabilidade pela coerção, ou seja, uma forma compensatória quando em déficit moral. Deste modo, é visto que se delineava uma noção de complementariedade entre moral e direito. Habermas lança mão do princípio do discurso que visa atingir a toda norma de ação. Por conseguinte, tal conceito se designa inicialmente tanto à normas morais quanto às jurídicas.

O princípio do Discurso afirma que "são válidas todas as normas de ação às quais todos os possíveis atingidos poderiam dar seu assentimento, na qualidade de participantes de discursos racionais" (HABERMAS, 2003, p.142). Inseridos dentro de uma teoria do discurso, portanto, estabelece um discurso racional que dá o critério para legitimidade. As normas morais partem de um assentimento e cooperação entre todos os envolvidos. Podemos dizer o mesmo sobre qualquer norma de ação, mesmo as jurídicas. No entanto, Habermas em Facticidade e Validade desenha um alinhamento complementar entre a moral e o direito.

Desta forma, mesmo que a moralidade e o direito tenham o mesmo princípio da gênese das normas de ação e coexistam sem subordinar uma a outra, no âmbito do direito as leis serão fundamentadas e legitimadas de modo singular à moral. Conforme podemos perceber, o princípio da moral resulta de uma especificação do princípio do discurso, ou seja, apesar de Habermas adotar o princípio do discurso como fundamentação de regras morais, no desdobrar especifica-se à moral no princípio moral.

$\mathrm{Na}$ medida em que o princípio do discurso se mostra como princípio geral frente às diferentes normas de ação (morais e jurídicas), nada mais coerente que a 
especificação deste princípio em um princípio moral - em que as normas morais somente podem se justificar na medida em que se toma em conta o interesse por igual de todos (universalidade) (JUNIOR, 2005, p. 248.)

Como um especificação do Princípio do Discurso, Habermas lança mão do princípio da democracia: "O Princípio da Democracia resulta de uma especificação correspondente para tais normas de ação que surgem na forma do direito e que podem ser justificadas com auxílio de argumentos pragmáticos, ético-políticos e morais - e não apenas com auxílio de argumentos morais" (HABERMAS, 2003. v.1. p. 143.).

Depreendemos que na obra facticidade e validade, Habermas apresenta um modelo de direito estritamente democrático e racional. Ainda que se atenha aos procedimentos lançados na $T A C$, é somente em entre facticidade e validade que Habermas lança um modelo absolutamente democrático. Vejamos a passagem:

O princípio da democracia explica, noutros termos, o sentido performativo da prática de autodeterminação de membros do direito que se reconhecem mutuamente como livres e iguais de uma associação estabelecida livremente. Por isso, o princípio da democracia não se encontra no mesmo nível do da moral (HABERMAS, 2003. v.1. p. 145).

Desta forma, embora haja uma co-originalidade entre direito e moral, não há aqui uma subvalorização de um ou em relação ao outro. Ainda, é observável a necessária relação do princípio da democracia na forma do direito e no código do direito dando sustentação a fundamentação e a legitimidade do direito.

Esses discursos não-morais operam na esfera externa, pois dizem respeito às considerações fora do âmbito moral, ou seja, a tudo que é pragmático e ético que é o mesmo que afirmar: nessa dimensão operacionalizam discursos acerca de tudo o que é não-moral, porém, de interesse jurídico.

Como já mencionado, o mundo da vida e o sistema (administrativo e econômico) mantém continuamente trocas, embora cada um possua uma lógica específica. Neste relacionamento de acoplamento e desacoplamento, o direito é um sistema, contudo, é um sistema diferenciado como medium, pois é o direito como medium e estatuído democraticamente, isto é, legitimamente capacitado para mediar o mundo da vida com os sistemas (e vice versa). Consoante Baxter,

A tarefa do "sistema de direitos" de Habermas é mediar duas tensões relacionadas: entre autonomia pública e privada e entre direitos básicos e soberania popular. Aqui, também, Habermas vê essas tensões como expressão de uma tensão mais geral entre facticidade e validade. Os direitos individuais básicos criam esferas de ação moralmente neutralizada, garantindo assim a autonomia privada dos indivíduos. Mas esses direitos devem ser justificados e legitimados por meio de um processo legislativo baseado no "princípio da soberania popular". A ideia do sistema de direitos de Habermas é mostrar que esses dois aspectos do direito moderno não são apenas compatíveis, mas "co-originais" (BAXTER, 2011, p.63-4).

De fato, a preocupação de encontrar o ponto arquimédico entre a tensão dos direitos fundamentais básicos e a soberania popular deve ser uma preocupação elementar para o Estado democrático de direito contemporâneo. A interrelação entre a tradição republicana e liberal necessitam, assim, uma fundamentação em termos de processos discursivos. Embora não seja aqui a intenção de auscultar os meandros da concepção de direito, vale afirmar que ele é posto em um patamar diferenciado na obra facticidade e validade, visto o papel definitivo que ele desenvolve na medição entre a relações do mundo da vida e dos subsistemas. 
Além do mais, ao que nos parece, Habermas se dá conta que o direito, embora como ultima ratio, é o único dispositivo capaz de garantir alguma estabilidade na cooperação social. Mesmo uma moral racional não consegue atingir um mínimo de segurança das relações interpessoais nas sociedades contemporâneas.

\section{CONSIDERAÇÕES FINAIS}

Apesar do profícuo esforço de Habermas em demonstrar que perseguimos entendimento e consenso, foco aliás do mundo da vida, não há como desconsiderar, em uma análise social, os desencontros e desentendimentos. Neste viés, a sua teoria não deixa de abordar o estudo dos dissensos. O mundo da vida tem sido alvo de produtos sistêmicos que têm deixado seu rastro em suas estruturas. Isso, é claro, tem de fazer Habermas abordar as patologias do mundo da vida que tem sido violentamente atingido pelos sistemas. Um mundo da vida que não se encontra orientado pelo sucesso, mas pelo entendimento é mais difícil de encontrar.

Então, poderíamos dizer que um mundo da vida, na pior das hipóteses, envolto por sistemas e, por vez, acuado não deixa de perseguir o seu destino nas suas estruturas intersubjetivas. Por mais que na maior parte do tempo indivíduos se sintam impelidos a agirem de maneira objetificadora, o mundo da vida, por meio de suas estruturas, sempre oferece o viés do entendimento como forma de organização.

$\mathrm{O}$ direito, em sua forma de fundamentação apresentada em facticidade $e$ validade, apresenta certo distanciamento da moralidade, embora, como Habermas enfatiza, são co-originais. A conjunção do princípio do discurso e forma jurídica garantem o espaço para legitimação e atuação do direito. Neste interim, a ideia de autolegislação, própria de uma tradição republicana, oferece o entendimento de que os indivíduos, na qualidade de destinatários, possam se entender também como autores do direito.

O direito parece-nos ser o dispositivo institucional e legitimado para oferecer uma possibilidade de pensar o mundo da vida descolonizado, ou ainda, um dispositivo capaz de oferecer certas barreiras a autonomia das estruturas do mundo da vida. Em face à força colonizadora do dinheiro e do poder, o direito, enquanto sistema de saber e sistema de ação, por meio dos processos democráticos institucionais, oferece meios e instrumentos para coordenar, orientar e decidir os dissensos que brotam nas relações entre os indivíduos e entre as estruturas/sistemas que fazem parte da vida em sociedade.

\section{REFERÊNCIAS}

BAXTER, Hugh. Habermas: The Discourse Theory of Law and Democracy. Stanford: Stanford University Press, 2011.

DEFLEM. Mathieu. Habermas, Modernity and Law. London: Sage Publication, 1996.

DURÃO, A. B. A Tensão Entre Facticidade e Validade no Direito Segundo Habermas. Ethica. Florianópolis: v.5, n.1, p.103 - 120, 2006.

FAIRTLOUGH. Gerald H. Habermas' Concept “Lifeworld”. Systems Practice. London: v. 4. n. 6, 1991. p.547-563.

HABERMAS, Jürgen. Direito e Democracia: entre facticidade e validade. Rio de Janeiro: Tempo Brasileiro, 2003.

HABERMAS, Jürgen. Teoria do agir comunicativo: Racionalidade da Ação e racionalização Social. v. i. São Paulo: Martins Fontes: 2012.

HABERMAS, Jürgen. Teoria do agir comunicativo: sobre a crítica da razão funcionalista. v. ii. 
São Paulo: Martins Fontes: 2012.

HABERMAS, Jürgen. Comentários à Ética do Discurso. Lisboa: Instituto Piaget, 1991.

HUNT, A; TWEEDY, J. The Future the Welfare State and Social Rights: Refletctions on Habermas. Journal of law and society. Cardiff Wales: v.21, n.3, 1994, p. 288-316.

HUSSERL, Edmund. A Crise das Ciências Europeias e a Fenomenologia Transcendental. 1. ed. Rio de Janeiro: Forense Universitária, 2012.

JUNIOR, Lúcio A. Chamon. Filosofia do Direito na Alta Modernidade: incursões teóricas nas Kelsen, Luhmann e Habermas. Rio de janeiro: Editora Lumens, 2005.

POPPER, Karl. Em busca de um mundo melhor. Lisboa: Fragmentos, 1988.

OLIVEIRA, M. A. Antropologia Filosófica Contemporânea: Subjetividade e Inversão Teórica. 1.ed. São Paulo: Paulus, 2012.

ROCHA, A. S. Estanqueiro. Democracia Deliberativa. In: ROSAS, João Cardoso. Manual de Filosofia Politica. Coimbra: Edições Almedina, 2008.

SCHÜTZ, Alfred. On Phenomenology and Social Relations. 2. ed. Chicago: The University of Chicago Press, 1973.

STEIN, Ernildo. As Ilusões da Transparência: Dificuldades com o Conceito de Mundo da Vida. 2. ed. Ijuí: Unijuí, 2012. 